\title{
Morphology, thermal and mechanical properties of biodegradable poly(butylene succinate)/poly(butylene adipate-co-terephthalate)/clay Nanocomposites.
}

\begin{abstract}
Sodium montmorillonite (Na-MMT) was successfully modified by octadecylamine (ODA) through a cation exchange technique that showed by the increased of basal spacing of clay by XRD. The addition of the organoclay into the PBS/PBAT blends produced intercalated-type nanocomposites with improvements in tensile modulus and strength. The highest tensile strength of nanocomposite was observed at $1 \mathrm{wt} \%$ of organoclay incorporated. A TGA study showed that the thermal stability of the blend increased after the addition of the organoclay by $1 \mathrm{wt} \%$. SEM micrographs of the fracture surfaces show that the morphology of the blend becomes smoother with presence of organoclay.
\end{abstract}

Keyword: Biodegradable; Nanocomposite; Organoclay. 